\title{
Hypermethylation of normal mucosa of esophagus-specific 1 is associated with an unfavorable prognosis in patients with non-small cell lung cancer
}

\author{
DONG SUN KIM ${ }^{1}$, WON KEE LEE ${ }^{2}$ and JAE YONG PARK ${ }^{3}$ \\ ${ }^{1}$ Department of Anatomy, BK21 Plus KNU Biomedical Convergence Program; \\ Departments of ${ }^{2}$ Preventive Medicine and ${ }^{3}$ Internal Medicine, School of Medicine, \\ Kyungpook National University, Daegu 702-422, Republic of Korea
}

Received November 21, 2017; Accepted April 27, 2018

DOI: $10.3892 /$ ol.2018.8915

\begin{abstract}
Lung cancer is the leading cause of cancer-associated mortality due to high incidence and poor survival rates, irrespective of global variations in its biology and treatment. Changes in DNA methylation are frequent in cancer and constitute an important mechanism in tumorigenesis. Normal mucosa of esophagus-specific 1 (NMES1) is expressed in epithelial tissue and is believed to be a tumor suppressor gene. The present study investigated the methylation status of the NMES1 promoter in 178 cases of primary non-small cell lung cancer (NSCLC) by pyrosequencing and evaluated the prognostic value of this methylation. NMES1 methylation-positive tumors above the background threshold for non-malignant tissue were found in 15 cases $(8.4 \%)$ and were detected exclusively in malignant tissues. In addition, univariate and multivariate analyses showed that methylation-positive patients experienced worse overall survival rate (OSR) compared with methylation-negative patients (adjusted hazard ratio, 2.62; 95\% confidence interval, 1.20-5.69; $\mathrm{P}=0.02)$. Notably, within the methylation-positive group, patients with strong methylation tended to experience worse OSR compared with those with weak methylation (adjusted hazard ratio, 2.45 vs. 3.05; $\mathrm{P}_{\text {trend }}=0.02$ ). These findings suggest that NMES1 may serve an important role in lung cancer pathogenesis, and its methylation could be considered a prognostic marker for NSCLC. Further studies with large numbers of samples are required to confirm this conclusion.
\end{abstract}

Correspondence to: Professor Jae Yong Park, Department of Internal Medicine, School of Medicine, Kyungpook National University, 2-101 Dongin-dong, Jung-gu, Daegu 702-422, Republic of Korea

E-mail: jaeyong@knu.ac.kr

Key words: non-small cell lung cancer, NMES1, hypermethylation, pyrosequencing, prognosis

\section{Introduction}

Although significant advances have been made toward the reduction of occupational health hazards associated with lung cancer, particularly smoking, and in the prevention of various disorders, lung cancer remains a highly lethal disease. Moreover, survival rates are not improving owing to late diagnosis and unsatisfactory monitoring for recurrence (therapy response) $(1,2)$. This makes the search for suitable biomarkers one of the highest priorities in the study of lung cancer $(3,4)$. Abnormal DNA methylation is an important epigenetic regulator of tumorigenesis (5). Deciphering common and specific DNA methylation patterns of cancerous tissue is essential for understanding tumor development. The potential use of gene methylation for the detection and diagnosis of lung cancer in biopsy specimens has been evaluated in several studies $(6,7)$.

Normal mucosa of esophagus-specific 1 (NMES1), also known as C15orf48, was first identified in a study of human esophageal squamous cell carcinoma (ESCC) tissues, which showed that its mRNA and protein levels were reduced in carcinoma samples (8). Overexpression of NMES1 inhibits cell motility in ESCC cell lines (9), suggesting its suppressive role in tumorigenesis in the esophagus. Furthermore, NMES1 transcripts have been found to be inactivated by DNA methylation in invasive cervical cancer and colon cancer $(10,11)$. Notably, NMES1 has been identified as a potential candidate for modifiers of susceptibility to skin tumor promotion by phorbol ester (12). NMES1 is mainly expressed in epithelial tissues, including weakly in the lungs (8), but the precise function of NMES1 remains unknown. To understand the biological role of NMES1 in lung cancer, pyrosequencing was conducted in the present study to investigate the methylation status of the NMES1 promoter in resected primary non-small cell lung cancer (NSCLC), and the association between these results and clinicopathological characteristics were assessed.

\section{Materials and methods}

Patients and tissue samples. Tumor and corresponding non-malignant lung tissue specimens $(n=178)$ between January 2002 and July 2010 were provided by the National 
Biobank of Korea, Kyungpook National University Hospital (KNUH; Daegu, South Korea), which is supported by the Ministry of Health, Welfare and Family Affairs. This study was conducted with the approval of the Ethics Committee of KNUH (approval no. 2014-04-210) All materials derived from the National Biobank of Korea, KNUH, were obtained following approval by the Institutional Review Board of KNUH and written informed consent was obtained from all of the participants prior to obtaining the samples. The clinicopathological characteristics of patients (mean age 64 years, range 35-83 years) are summarized in Table I. The pathological stage was determined by applying the seventh edition of the Union for International Cancer Control and American Joint Committee on Cancer TNM classification (13).

Cell culture and RT-PCR. A normal human lung epithelial cell line (BEAS-2B) and 12 human lung cancer cell lines (NCI-H522, NCI-H1703, NCI-H1299, NCI-H2108, NCI-H187, NCI-H2009, NCI-H520, NCI-H23, NCI-H1373, HCC827, PC9 and A549) were obtained from the American Type Culture Collection (Manassas, VA, USA). BEAS-2B and the cancer cell lines were maintained at $37^{\circ} \mathrm{C}$ with $5 \% \mathrm{CO}_{2}$ in Dulbecco's modified Eagle's medium/F12 and RPMI-1640 medium (Invitrogen; Thermo Fisher Scientific, Inc., Waltham, MA, USA), respectively, supplemented with $10 \%$ heat-inactivated fetal bovine serum (Invitrogen; Thermo Fisher Scientific, Inc.). NCI-H187 cells were treated with the demethylating agent 5-aza-2'-deoxycytidine (5-AzadC) for 3 days, with culture medium being changed daily. Total RNA was extracted from the cultured cells and primary tumor tissues using TRIzol reagent (Invitrogen; Thermo Fisher Scientific, Inc.). Subsequent to removing residual DNA, first-strand cDNA was synthesized from total RNA using SuperScript First-Strand Synthesis System (Invitrogen; Thermo Fisher Scientific, Inc.) according to the manufacturer's protocols. The resulting cDNA was amplified with sense primer 5'-AGG AACTCATTCCCTTGGTG-3' and antisense primer 5'-TCC ACAGTTTCCCAAGGTTC-3'. The PCR conditions were as follows: Denaturation at $95^{\circ} \mathrm{C}$ for $2 \mathrm{~min}$, then 30 cycles of $95^{\circ} \mathrm{C}$ for $1 \mathrm{~min}, 58^{\circ} \mathrm{C}$ for $1 \mathrm{~min}, 72^{\circ} \mathrm{C}$ for $1 \mathrm{~min}$, and final extension at $72^{\circ} \mathrm{C}$ for $5 \mathrm{~min}$. Glyceraldehyde 3-phosphate dehydrogenase $(G A P D H)$ was amplified with sense primer 5'-CATGACAAC TTTGGTATCGTG-3' and antisense primer 5'-GTGTCGCTG TTGAAGTCAGA-3' for the internal loading control. Amplified products were separated on $2 \%$ agarose gels, visualized with ethidium bromide and photographed by Syngene DigiGenius Gel Documentation system (Syngene, Frederick, MD, USA). Band intensities were quantified with ImageJ 1.50i program (National Institutes of Health, Bethesda, MD, USA) and the relative amount of NMES1 mRNA, normalized to GAPDH levels, was expressed as gray values.

Genomic DNA isolation and pyrosequencing. Genomic DNA was extracted using a QIAamp DNA Mini kit (Qiagen, Inc., Valencia, CA, USA) and was chemically modified with the EZ DNA Methylation-Gold kit (Zymo Research Corp., Irvine, CA, USA) according to the manufacturer's protocol. The methylation status of NMES1 was quantitatively determined by pyrosequencing. Briefly, bisulfate-modified DNA was PCR-amplified using forward primer 5'-TTATAAGTATTTAGGGGGGTT AAGA-3' and reverse primer biotin-5'-CCCCCTACAAAA
Table I. Association between methylation status of normal mucosa of esophagus-specific 1 and characteristics of non-small cell lung cancer patients.

\begin{tabular}{lcc}
\hline Variables & Methylation, n (\%) & P-value $^{\mathrm{a}}$ \\
\hline All subjects (n=178) & $15(8.4)$ & \\
Age, years & & 0.42 \\
$\leq 64(\mathrm{n}=80)$ & $5(6.3)$ & \\
$>64(\mathrm{n}=98)$ & $10(10.2)$ & 0.24 \\
Sex & & \\
Male $(\mathrm{n}=125)$ & $13(10.4)$ & \\
Female (n=53) & $2(3.8)$ & \\
Smoking status & & \\
Ever $(\mathrm{n}=120)$ & $13(10.8)$ & 0.05 \\
Never (n=58) & $2(3.4)$ & \\
Histological types & & \\
SCC $(\mathrm{n}=85)$ & $11(12.9)$ & \\
ADC $(\mathrm{n}=93)$ & $4(4.3)$ & \\
Pathological stage & & \\
Stage I $(\mathrm{n}=93)$ & $7(8.6)$ & \\
Stage II-IIIA (n=85) & $7(8.2)$ & \\
\hline
\end{tabular}

${ }^{a} \chi^{2}$ test. SCC, squamous cell carcinoma: ADC, adenocarcinoma.

CATTCTAC-3' with the GeneAmp Gold PCR Reagent kit (Applied Biosystems; Thermo Fisher Scientific, Inc.). The PCR conditions were as follows: Denaturation at $95^{\circ} \mathrm{C}$ for $10 \mathrm{~min}$, then 40 cycles of $95^{\circ} \mathrm{C}$ for $1 \mathrm{~min}, 55^{\circ} \mathrm{C}$ for $1 \mathrm{~min}, 72^{\circ} \mathrm{C}$ for $1 \mathrm{~min}$, and final extension at $72^{\circ} \mathrm{C}$ for $10 \mathrm{~min}$. PCR product quality and absence of contamination were confirmed by $2 \%$ agarose gels with ethidium bromide staining. Following purification of the PCR product using Sepharose beads on a PyroMark Vaccum Prep Workstation (Qiagen, Inc.), pyrosequencing was performed according to the manufacturer's specifications using a sequencing primer (5'-TAGGGGGGTTAAGAG-3') and a PyroMark Q96MD system (Qiagen, Inc.). The mean methylation index (MI) was calculated from the mean of the methylation percentage for the eight evaluated $\mathrm{CpG}$ sites. To set the controls for pyrosequencing, CpGenome ${ }^{\mathrm{TM}}$ Universal methylated and unmethylated DNA (Chemicon, Temecula, CA, USA) was used as a positive and negative control, with stable levels of methylation. Each pyrosequencing was repeated at least once to confirm the results.

Statistical analysis. The association between methylation status and clinicopathological characteristics was analyzed by a $\chi^{2}$ test for categorical variables. A logistic regression test was conducted to estimate the association between methylation and the covariates of age, sex, exposure to tobacco smoke and histology. The overall survival rate (OSR) of NSCLC patients according to NMES1 methylation status was compared using the Kaplan-Meier method and the log-rank test. Hazard ratios (HR) and 95\% confidence intervals (CIs) were estimated using the multivariate Cox proportional hazard model. $\mathrm{P}<0.05$ was considered to indicate a statistically significant difference. 


\section{A 156T}

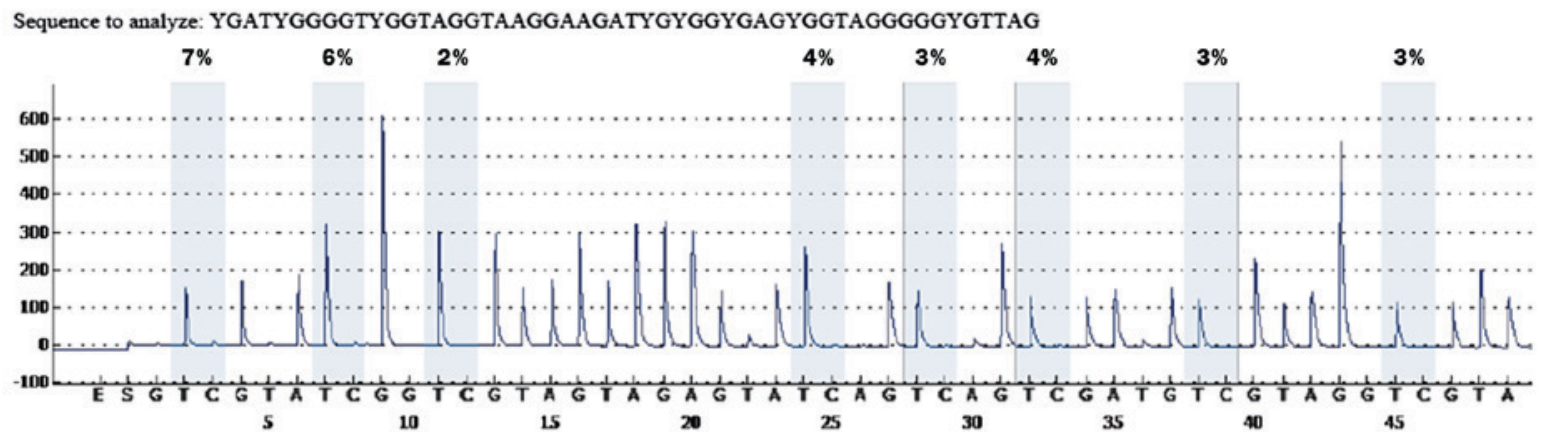

\section{B 160T}

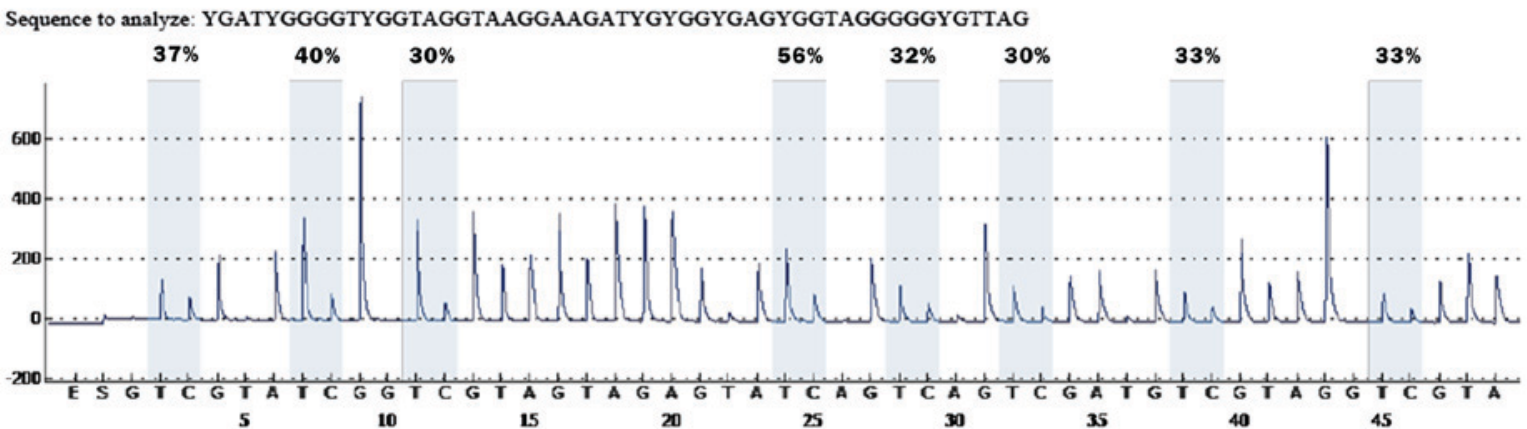

C UD

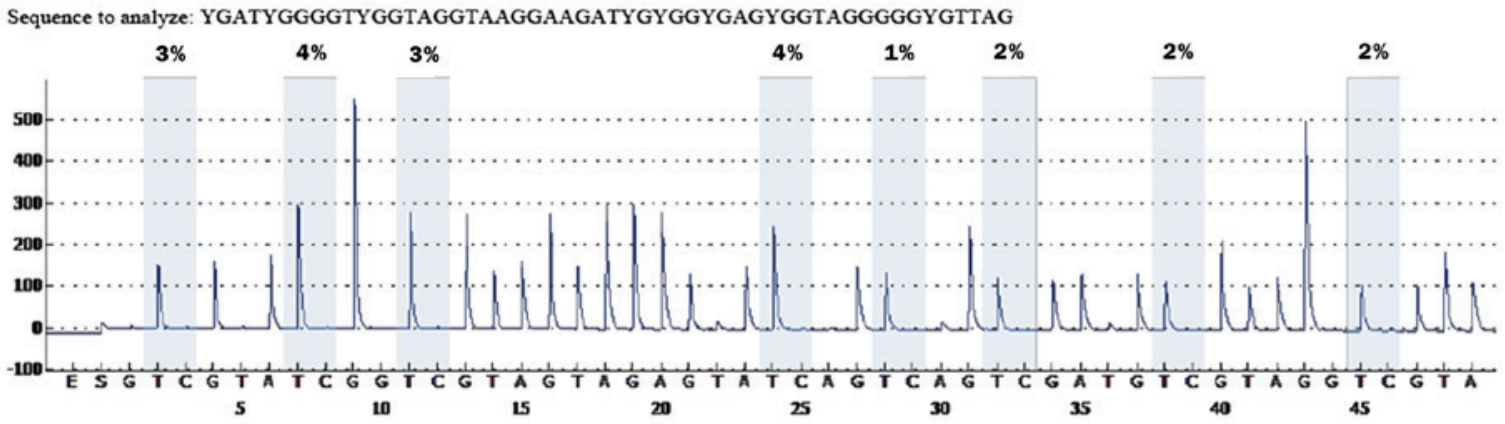

\section{MD}

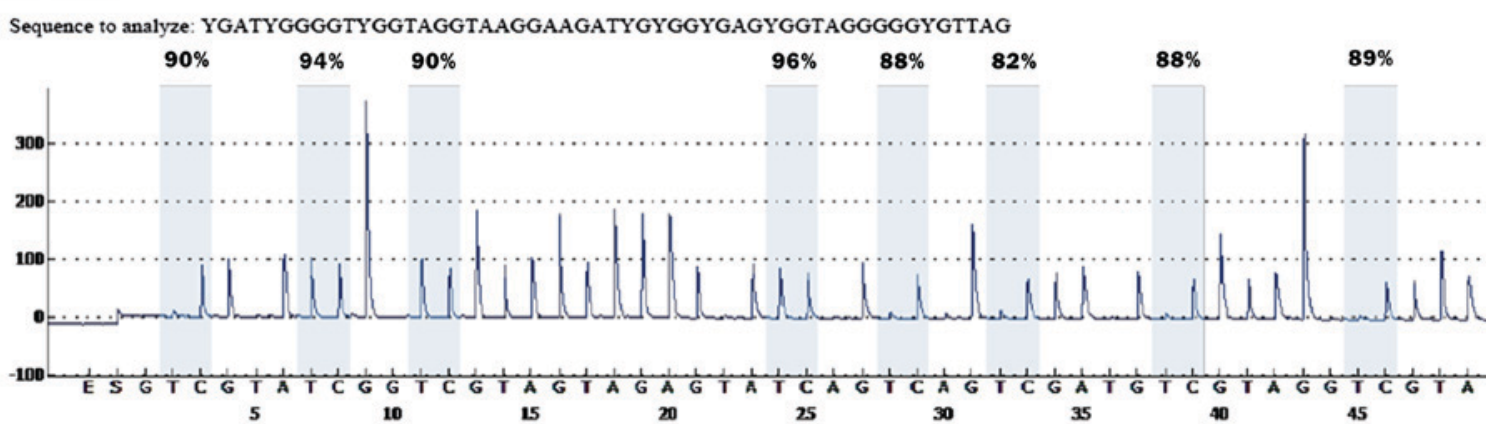

Figure 1. Representative pyrograms of normal mucosa of esophagus-specific 1 in non-small cell lung cancer patients. The letters on the axis represent the dispensation order: E, enzyme mix; S, substrate; A, G, C and T, nucleotides. Shaded bars encompassing T/C pairs indicate 8 interrogated CpGs. The methylation of each $\mathrm{CpG}$ site was calculated as a percentage of $\mathrm{C}$ incorporation.

\section{Results and Discussion}

Methylation status and expression of NMES1 in NSCLC samples. In the present study, pyrosequencing was performed to analyze the methylation status of the human NMES1 gene in 178 primary NSCLCs and corresponding non-malignant lung tissue controls. Given the presence of $\mathrm{CpG}$ islands (CGIs) in the NMES1 5'-flanking region, including the first exon, the pyrosequencing primer was designed so as to encompass 8 CpGs from - 165 to -115 bp upstream of the transcription start 
A Pyrosequencing analysis

\begin{tabular}{|c|c|c|c|c|c|c|c|c|c|c|c|c|c|}
\hline & 1 & 2 & 3 & 4 & 5 & 6 & 7 & 8 & 9 & 10 & 11 & 12 & 13 \\
\hline $\begin{array}{c}\text { Cell } \\
\text { lines }\end{array}$ & $\begin{array}{c}\mathrm{NCl} \\
\mathrm{H} 522\end{array}$ & $\begin{array}{c}\mathrm{NCl}- \\
\mathrm{H} 1703\end{array}$ & $\mathrm{PC9}$ & $\begin{array}{c}\mathrm{NCl}- \\
\mathrm{H} 1299\end{array}$ & $\mathrm{~A} 549$ & $\begin{array}{c}\mathrm{NCl} \\
\mathrm{H} 2108\end{array}$ & $\begin{array}{c}\mathrm{BEAS} \\
-2 \mathrm{~B}\end{array}$ & $\begin{array}{c}\mathrm{NCl}- \\
\mathrm{H} 187\end{array}$ & $\begin{array}{c}\mathrm{NCl}- \\
\mathrm{H} 2009\end{array}$ & $\begin{array}{c}\mathrm{NCl}- \\
\mathrm{H} 520\end{array}$ & $\begin{array}{c}\mathrm{NCl}- \\
\mathrm{H} 23\end{array}$ & $\begin{array}{c}\mathrm{HCC} \\
827\end{array}$ & $\begin{array}{c}\mathrm{NCl}- \\
\mathrm{H} 1373\end{array}$ \\
\hline $\mathrm{Ml}(\%)$ & 2.0 & 1.9 & 35.6 & 1.9 & 1.1 & 3.0 & 2.4 & 2.5 & 43.1 & 3.8 & 1.9 & 2.8 & 3.7 \\
\hline
\end{tabular}

\section{B RT-PCR analysis}

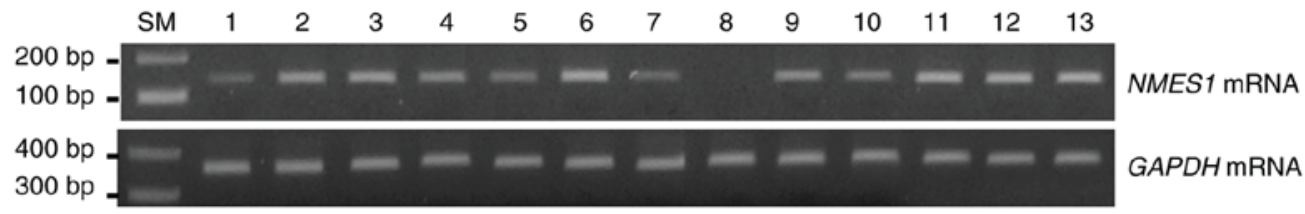

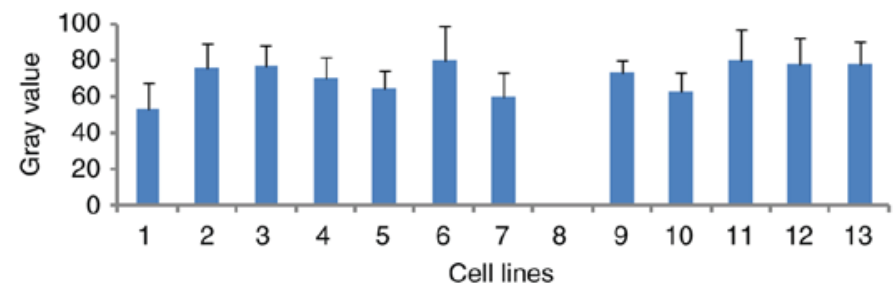

Figure 2. Pyrosequencing and RT-PCR analysis of NMES1 in non-small cell lung cancer cell lines. (A) NMES1 methylation status in 13 cell lines, as determined by pyrosequencing. (B) NMES1 mRNA expression in the same cell lines, as determined by semiquantitative RT-PCR (top). GAPDH was used as an internal loading control. Band intensities were quantified with the ImageJ 1.50i program and the relative amount of NMES1 mRNA, normalized to GAPDH levels, was expressed as gray values (bottom). SM, 100-bp DNA ladder. NMES1, normal mucosa of esophagus-specific 1; RT-PCR, reverse transcription-polymerase chain reaction; GAPDH, glyceraldehyde 3-phosphate dehydrogenase.

site. Consistently, Arai et al (9) previously demonstrated a high degree of DNA methylation within the same region in ESCC. Accurate and reproducible estimates of methylated cytosine content were obtained in all tested samples, and representative pyrograms are shown in Fig. 1. Pyrosequencing of the representative PCR products showed that all cytosines at non- $\mathrm{CpG}$ sites were converted to thymines, ruling out the possibility of incomplete bisulfite conversion. Considering a mean MI of $7.10 \%$ for all non-malignant lung tissues, 7.10 was set as a cut-off point for a methylation-positive classification (data not shown). NMES1 methylation was detected exclusively in malignant tissues, at a frequency of $8.4 \%$ (15/178), suggesting that NMES1 promoter methylation may be a tumor-associated event during NSCLC tumorigenesis. These results represent the first demonstration of aberrant methylation of NMES1 in primary tumors of NSCLC patients. Furthermore, using an average MI of $28.95 \%$ for 15 methylated samples as a cut-off value (data not shown), methylation-positive tumors were divided into two groups, weak methylation $(7.10 \leq \mathrm{MI}<28.95)$ and strong methylation ( $\mathrm{MI} \geq 28.95)$. Accordingly, 10 cases were assigned to the weak methylation group and 5 to the strong methylation group. Although there is no reasonable rationale to use median MI for assigning certain specimens to the weak or the strong methylation groups, this approach was followed based on the observation of a previous study (13). Originally, Shaw et al (14) divided methylated samples into weak- and strong-methylation groups based on a median split, which is necessary to silence mRNA expression of the corresponding genes. In our previous study, using the log-rank test for patient OSR through a series of methylation levels measured by pyrosequencing revealed that the lowest $\mathrm{P}$-value is observed around the median level (15).
To determine whether promoter methylation could be involved in the regulation of NMES1 expression, NMES1 mRNA levels were analyzed in 13 human lung cancer cell lines. Methylation status combined with RT-PCR findings showed that NMES1 mRNA was present in PC9 and NCI-H2009 cells with methylated alleles ( $\mathrm{MI}=35.6$ and $\mathrm{MI}=43.1$, respectively), but was absent in NCI-H187 cells without methylated alleles $(\mathrm{MI}=2.5)$ (Fig. 2A and B). Moreover, NCI-H187 cells failed to restore their native expression level following 5-AzadC treatment (data not shown). The correlation between CGI hypermethylation and NMES mRNA expression in weak and strong methylation groups was assessed. However, the NMES1 expression could not be evaluated according to methylation degree (such as negative, weak and strong) in cancer tissues owing to no preparation of total RNAs to ideally match all malignant tissues with weak or strong methylation (data not shown). These results suggest that CGI hypermethylation may not be associated with NMESI silencing; instead, other mechanisms may control its expression. This observation does not fit into the classical paradigm showing an inverse correlation between DNA methylation and gene expression (16). Unexpectedly, integration of DNA methylation profiles and mRNA expression data in lung adenocarcinoma has indicated that approximately one-third of genes, which are differentially methylated between tumors and normal tissue, show concurrent changes in gene expression (17). Accordingly, regulation through DNA methylation is likely more complex than previously anticipated. The identification of long-range DNA methylation, spreading of DNA methylation and DNA methylation just outside CGIs add increasing intricacy to the association between DNA methylation and gene expression $(18,19)$. Alternatively, different CGIs or CpG sites within a CGI could have differential effects on gene expression $(20,21)$. 
Table II. Overall survival according to normal mucosa of esophagus-specific 1 methylation in non-small cell lung cancer patients.

\begin{tabular}{|c|c|c|c|c|c|c|c|c|}
\hline \multirow[b]{2}{*}{ Variables } & \multirow[b]{2}{*}{ Cases, n } & \multirow[b]{2}{*}{$\begin{array}{c}\text { Mortality, } \\
\mathrm{n}(\%)^{\mathrm{a}}\end{array}$} & \multirow[b]{2}{*}{$\begin{array}{c}\text { 5-year } \\
\text { survival rate }^{\mathrm{b}}\end{array}$} & \multirow[b]{2}{*}{$\mathrm{P}_{\mathrm{LR}}$} & \multicolumn{2}{|l|}{ Crude } & \multicolumn{2}{|c|}{ Adjusted } \\
\hline & & & & & $\begin{array}{c}\mathrm{HR} \\
(95 \% \mathrm{CI})\end{array}$ & P-value & $\begin{array}{c}\mathrm{HR} \\
(95 \% \mathrm{CI})^{\mathrm{c}}\end{array}$ & P-value \\
\hline All subjects & 178 & & & & & & & \\
\hline Non-methylation & 163 & $38(23.3)$ & 63 & & 1.00 & & 1.00 & \\
\hline Methylation & 15 & $9(60.0)$ & 32 & 0.02 & $2.30(1.11-4.76)$ & 0.03 & $2.62(1.20-5.69)$ & 0.02 \\
\hline Non-methylation & 163 & $38(23.3)$ & 63 & 0.04 & 1.00 & & 1.00 & \\
\hline Weak methylation & 10 & $6(60.0)$ & 40 & & $1.98(0.84-4.68)$ & 0.12 & $2.45(0.99-6.11)$ & 0.05 \\
\hline Strong methylation & 5 & $3(60.0)$ & 0 & & $3.44(1.04-11.39)$ & 0.04 & $3.05(0.84-11.06)$ & 0.09 \\
\hline$P_{\text {trend }}$ & & & & & 0.01 & & 0.02 & \\
\hline
\end{tabular}

${ }^{a}$ Row percentage. ${ }^{b}$ Proportion of survival derived from Kaplan-Meier analysis. ${ }^{~} \mathrm{HRs}, 95 \%$ CIs and their corresponding P-values were calculated using multivariate Cox proportional hazard models, adjusted for age, sex, smoking status, histology and pathological stage. HR, hazard ratio; CI, confidence interval; $\mathrm{P}_{\mathrm{LR}}$, log-rank P-value.
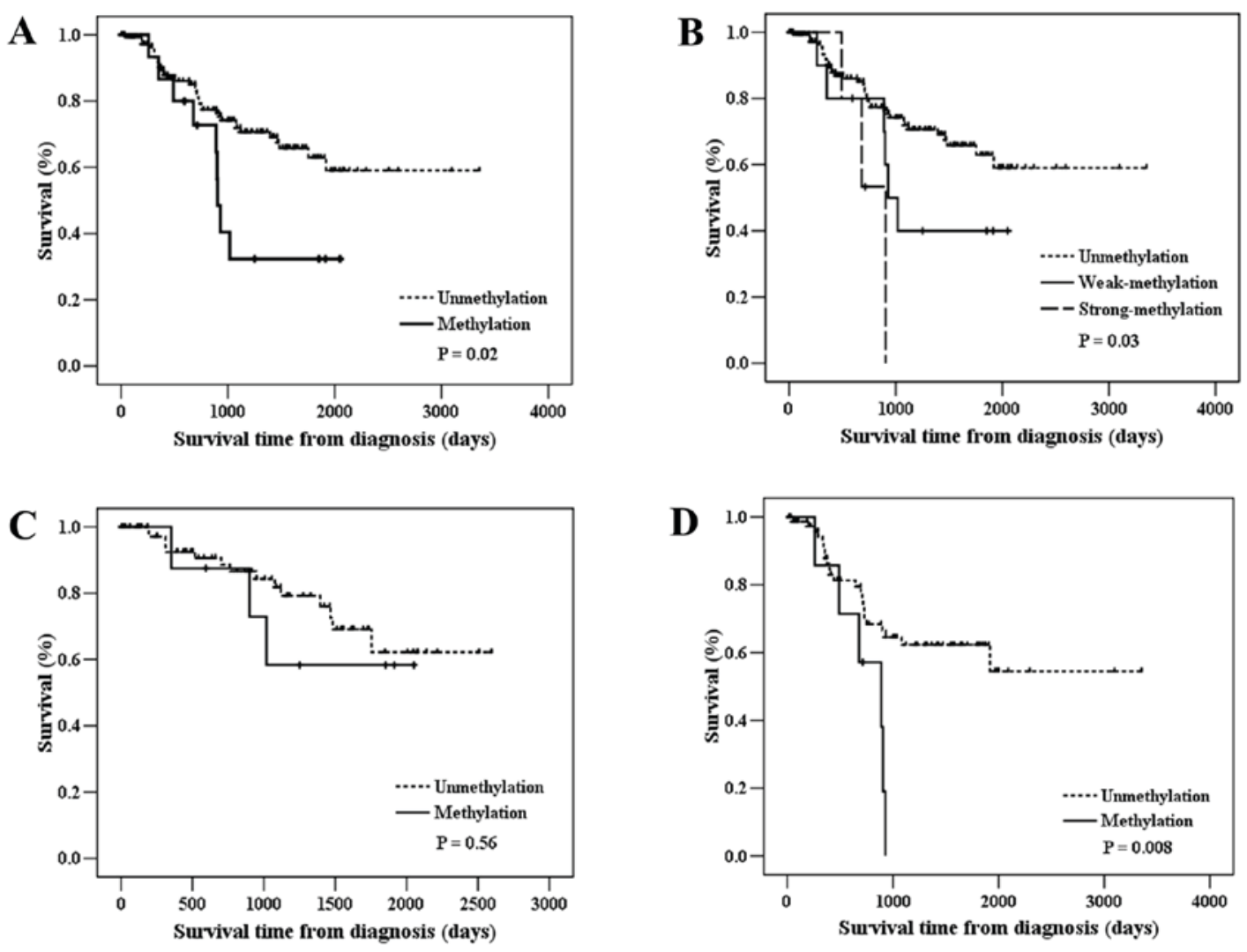

Figure 3. Association of NMES1 methylation with unfavorable prognosis in non-small cell lung cancer patients. Kaplan-Meier survival curves of (A and B) total patients, (C) patients with stage I disease and (D) patients with stage II-IIIA disease as a function of NMES1 methylation status or level. P-values are based on the log-rank test. NMES1, normal mucosa of esophagus-specific 1.

Moreover, single CGI methylation is not sufficient to maintain silencing (22). It could be speculated that other sites instead of the regions analyzed in the present study may be directly associated with NMESI expression. Subsequently, the $5 \mathrm{CpGs}$ that were located at the -397 to -357 region by pyrosequencing were investigated, showing no significant hypermethylation in malignant tissues compared with that in non-malignant tissues (data not shown). An attempt was made to compare the methylation of $6 \mathrm{CpGs}$ at the transcription start site, but no pyrosequencing primer with a high score was available (data not shown). Therefore, additional research is required to clarify the mechanism regulating NMESI expression.

Association of NMES1 promoter methylation with clinicopathological parameters and clinical outcomes. NMES1 promoter methylation was significantly more frequent in squamous cell 
carcinoma than in adenocarcinoma $(\mathrm{P}=0.05$; Table I). However, no significant correlation was observed between methylation and any other factors, including age, sex, smoking status and pathological stage (Table I). Next, Kaplan-Meier survival analysis was performed to determine the prognostic potential of NMES1 methylation. Notably, methylation-positive patients had worse OSR compared with methylation-negative patients [log-rank $\left.\mathrm{P}\left(\mathrm{P}_{\mathrm{LR}}\right)=0.02\right]$ (Table II and Fig. 3A). Notably, patients with strong methylation exhibited significantly reduced OSR, compared with those with weak methylation (HRadj, 3.05 vs. 2.45; $\mathrm{P}_{\text {trend }}=0.02$ ) (Table II and Fig. 3B), indicating that CGI methylation levels could influence the OSR. When stratified according to clinicopathological patient characteristics, NMESI methylation was significantly associated with unfavorable survival in patients with stage II-IIIA disease $\left(\mathrm{P}_{\mathrm{LR}}=0.008\right)$, but not in patients with stage I disease (Fig. 3C and D). To evaluate NMES1 methylation as an independent prognostic factor in NSCLC, the data was further analyzed using the Cox proportional hazards regression adjusting for possible confounders of survival. NMES1 methylation was significantly associated with worse OSR in all patients [adjusted HR (HRadj), 2.62; 95\% CI, 1.20-5.69; $\mathrm{P}=0.02]$. It is now known that NMES1 regulates cancer cell motility and is a component of mitochondrial respiratory chain complex IV $(9,23)$. Importantly, a growing body of evidence has demonstrated that tumor cells have defective mitochondrial respiration due to their dominant glycolytic metabolism (24). However, the precise function of NMES1 remains elusive. It is also difficult to imagine how methylated NMES1 would have any consequence in the tumorigenesis of lung cancer if mRNA expression and methylated DNA levels do not match. In addition to gene transcription repression, DNA methylation may also be important for alternative splicing, gene mutation and chromatin remodeling (25-27). Taken together, these results suggest that NMES1 may serve an important role in lung cancer pathogenesis and its methylation could be considered a prognostic marker for NSCLC patients. The present observations may offer novel insights for the clinical management of pyrosequencing-derived methylation levels.

The present study has several limitations. First, the retrospective design and small number of sample cases could confer potential selection bias in results interpretation. Second, there is a shortage of information on qPCR and NMES1 expression according to methylation degree in the tumor tissues. Finally, there is no reasonable rationale to use median MI for assigning certain specimens to the weak or the strong methylation groups.

The present study has shown that the NMES1 promoter was methylated exclusively in tumor tissues of NSCLCs and that its methylation was associated significantly with unfavorable OSR in those patients. Although the current study did not offer a complete overview due the small sample size and lack of information on protein expression, it is the first report to demonstrate aberrant methylation of NMESI in NSCLC and it provides clinical evidence to support the tumor-suppressing role of NMES1 in NSCLC. Future studies with larger sample sizes are required to confirm this conclusion.

\section{Acknowledgements}

Not applicable.

\section{Funding}

The present study was supported by a grant from the Korea Health Technology R\&D Project through the Korea Health Industry Development Institute, funded by the Ministry of Health and Welfare (grant no. HI4C0402).

\section{Availability of data and materials}

The analyzed datasets generated during the study are available from the corresponding author on reasonable request.

\section{Authors' contributions}

DSK contributed to the experimental design and implementation, performed the experiments and data analysis, and drafted the manuscript. WKL performed statistical analyses. JYP contributed to experiment implementation, interpreted the patient data and modified the manuscript. All authors have read and approved the final manuscript.

\section{Ethics approval and consent to participate}

The present study was approved by the Ethics Committee of Kyungpook National University Hospital (2014-04-210). Written informed consent was obtained from all participants or their families prior to obtaining the samples.

\section{Consent for publication}

All participants provided written informed consent for publication of any associated data and accompanying images.

\section{Competing interests}

The authors declare that they have no competing interests.

\section{References}

1. Siegel R, Ma J, Zou Z and Jemal A: Cancer statistics, 2014. CA Cancer J Clin 64: 9-29, 2014.

2. McIntyre A and Ganti AK: Lung cancer-A global perspective. J Surg Oncol 115: 550-554, 2017.

3. I H and Cho JY: Lung cancer biomarkers. Adv Clin Chem 72: 107-170, 2015.

4. Vargas AJ and Harris CC: Biomarker development in the precision medicine era: Lung cancer as a case study. Nat Rev Cancer 16: 525-537, 2016.

5. Baylin SB and Jones PA: A decade of exploring the cancer epigenome-biological and translational implications. Nat Rev Cancer 11: 726-734, 2011.

6. Liloglou T, Bediaga NG, Brown BR, Field JK and Davies MP: Epigenetic biomarkers in lung cancer. Cancer Lett 342: 200-212, 2014.

7. Walter K, Holcomb T, Januario T, Yauch RL, Du P, Bourgon R, Seshagiri S, Amler LC, Hampton GM and S Shames D: Discovery and development of DNA methylation-based biomarkers for lung cancer. Epigenomics 6: 59-72, 2014.

8. Zhou J, Wang H, Lu A, Hu G, Luo A, Ding F, Zhang J, Wang X, Wu M and Liu Z: A novel gene, NMES1, downregulated in human esophageal squamous cell carcinoma. Int J Cancer 101: 311-316, 2002.

9. Arai M, Imazeki F, Sakai Y, Mikata R, Tada M, Seki N, Shimada H, Ochiai T and Yokosuka O: Analysis of the methylation status of genes up-regulated by the demethylating agent, 5-aza-2'-deoxycytidine, in esophageal squamous cell carcinoma. Oncol Rep 20: 405-412, 2008. 
10. Sova P, Feng Q, Geiss G, Wood T, Strauss R, Rudolf V, Lieber A and Kiviat N: Discovery of novel methylation biomarkers in cervical carcinoma by global demethylation and microarray analysis. Cancer Epidemiol Biomarkers Prev 15: 114-123, 2006.

11. Spisák S, Kalmár A, Galamb O, Wichmann B, Sipos F, Péterfia B Csabai I, Kovalszky I, Semsey S, Tulassay Z and Molnár B: Genome-wide screening of genes regulated by DNA methylation in colon cancer development. PLoS One 7: e46215, 2012.

12. Riggs PK, Angel JM, Abel EL and Digiovanni J: Differential gene expression in epidermis of mice sensitive and resistant to phorbol ester skin tumor promotion. Mol Carcinog 44: 122-136, 2005.

13. Detterbeck FC, Boffa DJ and Tanoue LT: The new lung cancer staging system. Chest 136: 260-271, 2009.

14. Shaw RJ, Hall GL, Lowe D, Bowers NL, Liloglou T, Field JK, Woolgar JA and Risk JM: CpG island methylation phenotype (CIMP) in oral cancer: Associated with a marked inflammatory response and less aggressive tumour biology. Oral Oncol 43: 878-886, 2007.

15. Lee SM, Lee WK, Kim DS and Park JY: Quantitative promoter hypermethylation analysis of RASSF1A in lung cancer: Comparison with methylation-specific PCR technique and clinical significance. Mol Med Rep 5: 239-244, 2012.

16. Deaton AM and Bird A: $\mathrm{CpG}$ islands and the regulation of transcription. Genes Dev 25: 1010-1022, 2011.

17. Selamat SA, Chung BS, Girard L, Zhang W, Zhang Y Campan M, Siegmund KD, Koss MN, Hagen JA, Lam WL, et al: Genome-scale analysis of DNA methylation in lung adenocarcinoma and integration with mRNA expression. Genome Res 22 : $1197-1211,2012$

18. Bert SA, Robinson MD, Strbenac D, Statham AL, Song JZ, Hulf T, Sutherland RL, Coolen MW, Stirzaker C and Clark SJ: Regional activation of the cancer genome by long-range epigenetic remodeling. Cancer Cell 23: 9-22, 2013.

19. Irizarry RA, Ladd-Acosta C, Wen B, Wu Z, Montano C, Onyango P, Cui H, Gabo K, Rongione M, Webster M, et al: The human colon cancer methylome shows similar hypo- and hypermethylation at conserved tissue-specific $\mathrm{CpG}$ island shores. Nat Genet 41: 178-186, 2009.

20. Kim DS, Lee SM, Yoon GS, Choi JE and Park JY: Infrequent hypermethylation of the PTEN gene in Korean non-small cell lung cancers. Cancer Sci 101: 568-572, 2010.
21. Lessi F, Beggs A, de Palo M, Anti M, Macarone Palmieri R, Francesconi S, Gomes V, Bevilacqua G, Tomlinson I and Segditsas S: Down-regulation of serum/glucocorticoid regulated kinase 1 in colorectal tumours is largely independent of promoter hypermethylation. PLoS One 5: e13840, 2010.

22. Braga LC, Silva LM, Ramos AP, Piedade JB, Vidigal PV, Traiman $P$ and da Silva Filho AL: Single $\mathrm{CpG}$ island methylation is not sufficient to maintain the silenced expression of CASPASE- 8 apoptosis-related gene among women with epithelial ovarian cancer. Biomed Pharmacother 68: 87-91, 2014

23. Floyd BJ, Wilkerson EM, Veling MT, Minogue CE, Xia C, Beebe ET, Wrobel RL, Cho H, Kremer LS, Alston CL, et al: Mitochondrial protein interaction mapping identifies regulators of respiratory chain function. Mol Cell 63: 621-632, 2016.

24. Garcia-Heredia JM and Carnero A: Decoding Warburg's hypothesis: Tumor-related mutations in the mitochondrial respiratory chain. Oncotarget 6: 41582-41599, 2015.

25. Maunakea AK, Chepelev I, Cui K and Zhao K: Intragenic DNA methylation modulates alternative splicing by recruiting $\mathrm{MeCP} 2$ to promote exon recognition. Cell Res 23: 1256-1269, 2013

26. Hitchins MP, Rapkins RW, Kwok CT, Srivastava S, Wong JJ, Khachigian LM, Polly P, Goldblatt J and Ward RL: Dominantly inherited constitutional epigenetic silencing of MLH1 in a cancer-affected family is linked to a single nucleotide variant within the 5'UTR. Cancer Cell 20: 200-213, 2011.

27. Forn M, Muñoz M, Tauriello DV, Merlos-Suárez A, Rodilla V, Bigas A, Batlle E, Jordà M and Peinado MA: Long range epigenetic silencing is a trans-species mechanism that results in cancerspecific deregulation by overriding the chromatin domains of normal cells. Mol Oncol 7: 1129-1141, 2013.

This work is licensed under a Creative Commons Attribution-NonCommercial-NoDerivatives 4.0 International (CC BY-NC-ND 4.0) License. 